Portland State University

PDXScholar

Civic Art Lab

Archive Organized by Project Title

$10-12-2019$

\title{
Civic Art Lab: Reflections on Art, Design and Sustainability
}

Jeff Kasper

Laura Scherling

Follow this and additional works at: https://pdxscholar.library.pdx.edu/civic_art_lab Let us know how access to this document benefits you.

\section{Recommended Citation}

Kasper, Jeff and Scherling, Laura, "Civic Art Lab: Reflections on Art, Design and Sustainability" (2019). Civic Art Lab. 1.

https://pdxscholar.library.pdx.edu/civic_art_lab/1

This Book is brought to you for free and open access. It has been accepted for inclusion in Civic Art Lab by an authorized administrator of PDXScholar. Please contact us if we can make this document more accessible: pdxscholar@pdx.edu. 
Marchart, Oliver (2007): Post-Foundational Thought: Political Difference in Badiou and Laclau, Edinburgh: Edinburgh University Press.

Nancy, Lefort, Badiou and Lonistics: Thinking the World Politically, London and Mouffe, Chantal (2013): Agonis New York: Verso.

Parker, Jenneth (2014): Critiquing Sustainability, Changing Philosophy, Oxon and New York: Routledge.

Rosenberg, Jordana (2014): "The Molecularlization of Sexuality: On Some Primitivisms of the Present." In: Theory \& Event 17/2, n. p. (accessed through Project MUSE).

Schmidt, Carl (1996 [1932]): The Concept of the Political, Chicago and London University of Chicago Press.

Strathausen, Carsten (2006): "A Critique of Neo-Left Ontology" (http://pmc.iath virginia.edu/text-only/issue.506/16.3strathausen.txt).

trathausen, Carsten, (ed.) (2009): A Leftist Ontology: Beyond Relativism and Identity Politics, Minneapolis and London: University of Minnesota Press.

(2009): "Gramsci and the political: From the state as 'metaphysical

Thomas, Peter (2009): 'Cphilosophical fact."' In: Radical Philosophy 153, pp. $27-36$

\section{Civic Art Lab}

Reflections on Art, Design, and Sustainability ${ }^{1}$

\section{LAURA SCHERLING AND JEFF KASPER}

Picture 1: Civic Art Lab installation detail

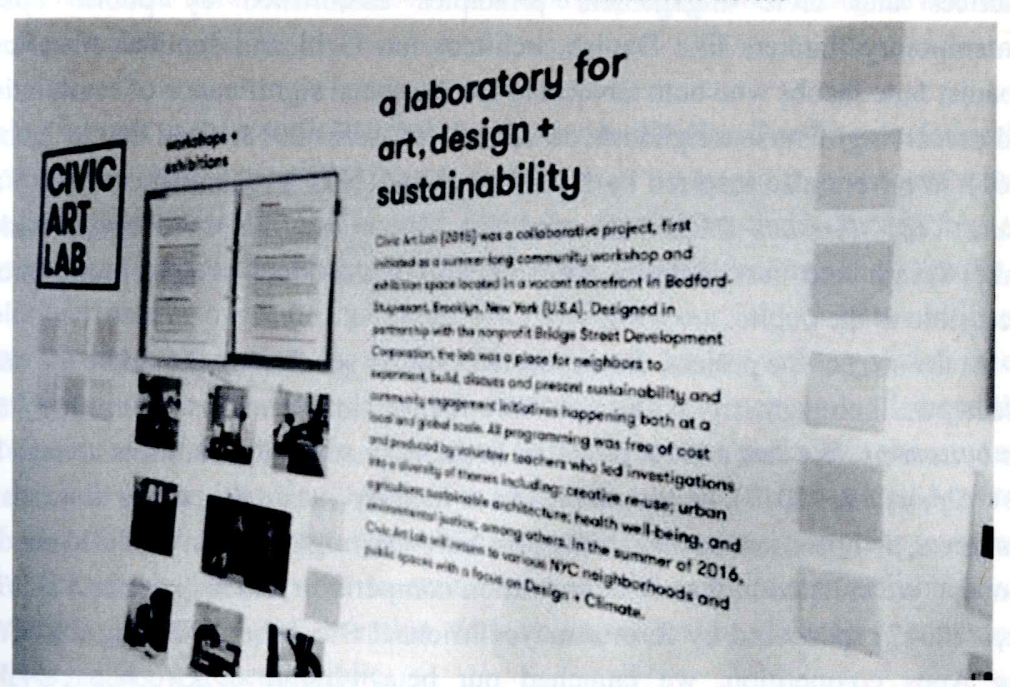

International Graduate Centre for the Study of Culture (GCSC), Justus-Liebig-University Giessen 2016. Courtesy of the authors.

1 This essay emerges out of the exhibition For What It's Worth: Creative Encounters, in which the authors participated, held at the International Graduate Centre for the Study of Culture (GCSC) at Justus Liebig University Giessen between April 28 and 30, 2016. 
to covering an old façade with yarn graffiti, or using a rehabilitated lot to host classes (cf. Debusmann 2011; Derringer 2013; Project for Public Spaces 2015).

As the excitement and dynamism of competing in NYC Big Apps wound down, our newly formed group had to decide where next to take the project. Paimaan Lodhi, an urban planner from Harlem Community Board 10, reached out to encourage GreenspaceNYC to get involved in transforming the type of sites that we were interested in supporting with our mobile app prototype. He emphasized that direct, tactical, creative interventions would be beneficial to pursue. We kept our notes from the meeting with Paimaan in the March of 2011, jotting down our thoughts at the time:

Paimaan gave us some excellent advice. See what others are doing... reach out to them on a grassroots level, and bring topics of advocacy back to our own network. It makes sense and it's a great way to develop the project. This is an exciting next step. It means we can do some actual field work. GreenspaceNYC is a valid project and worth taking the next steps. (Authors' notes)

Being invited to meet with Paimaan Lodhi was motivational and a transformative moment for GreenspaceNYC. Not long after that, we began to pivot into a nonprofit collaboration with a revised focus in developing and curating free art, design, and sustainability interventions. ${ }^{3}$ With limited funding and a group of volunteer instructors and organizers, we redesigned our initiative. We built our network on meetup.com by word of mouth and across various social media platforms. In the following years we created a series of pop-up workshops that took place in multiple venues - including in hackerspaces, parks, warehouses, and at cultural venues like New Museum's IdeasCity and The Staten Island Museum (cf. Ideas City 2018). Today, our public programs continue to take place in a range of spaces from public parks to community centers to vacant storefronts. Each project is created in collaboration with volunteer artists, designers, educators, activists, and the general public.

3 In 2012, GreenspaceNYC became fiscally sponsored by Fractured Atlas, giving it its status as a federally approved $501(\mathrm{c})(3)$ nonprofit. We gained material sponsorship from Materials for the Arts, a municipal program that is managed in collaboration with three city agencies, namely the NYC Department of Cultural Affairs, the NYC Department of Sanitation, and the NYC Department of Education.
2 GreenspaceNYC and Civic Art Lab were founded in 2011 by Laura Scherling, Jeff Kasper, Raymond Manalo, and Laurence Wilse-Samson. 


\section{MAKING: CIVIC ART LAB AND STOREFRONT EdUCATION}

After several years in operation, and with success in fine-tuning our public design and sustainability events and workshops, we wanted to increase our engagement in sustainability education should be more widely accessible to the public. We initiated Civic Art Lab as a summer-long community workshop and exhibition space located in a vacant storefront in the Bedford-Stuyvesant (Bed-Stuy) neighborhood in Brooklyn, New York. The design and build-out of the vacant storefront was led by architects Andrew Haner and Daniel Horn, architect and Wilford, and sustainability researcher Grace H. Johnson.

The workshop space, gallery, storage, and lounge were constructed from

The workshop space, gaterials. Designed in partnership recycled, upcycled, with the nonprofit Bridge Street Development suina and community neighbors to experiment, build, discuss and probal scale. ${ }^{4}$ engagement initiatives that happened both at a local and global scale.

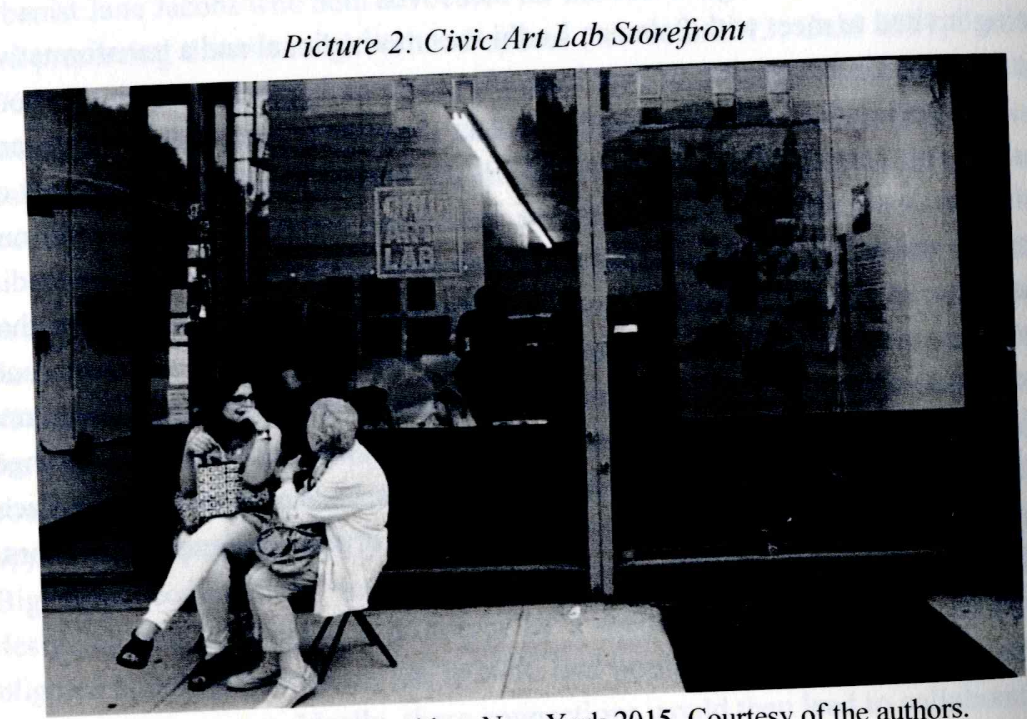

Bedford-Stuyvesant, Brooklyn, New York 2015. Courtesy of the authors.

The Bed-Stuy lab was sponsored through Bridge Street Development Corporation's Pop-up Program, and we received additional support from a

4 More information about the events and workshops is given in the 'Dialogue as selfreflection' section of this chapter.
Mojdeh Baratloo Urban Urge Award seed grant, Big Reuse, Materials for the Arts, and an $I O B Y$ fundraising campaign. ${ }^{5}$ The lab ran for six weeks. During this period, we offered 40 free design and sustainability-themed workshops. The lab incorporated a decentralized approach to workshop design, which allowed volunteers to assume various roles and responsibilities. After the lab concluded, we continued to pursue the project. GreenspaceNYC and Civic Art Lab, which had grown up out of a rapid prototype design, had now become embedded in our daily lives and our worldview.

In its $2^{\text {nd }}$ and $3^{\text {rd }}$ years, Civic Art Lab took place in Alphabet City, a neighborhood of New York City's borough of Manhattan. The lab occupied the local storefront Creations Gallery, which is adjacent to a family-owned bike repair shop in a mixed-use East Village building. Our programming continued to be free of cost thanks also to small donations by attendees and ongoing support from the city. Civic Art Lab workshops and exhibitions in 2016 and 2017 were respectively themed around the topics 'Design + Climate' and 'Resistance.' These workshops and exhibitions were produced by volunteer artists, designers, and teachers who led investigations into a diverse set of themes such as creative re-use, sustainable architecture, health and well-being, recycling, and environmental justice. ${ }^{6}$

The physical nature of Civic Art Lab as a community space in a vacant storefront and, by result, how that space informs the form of social relationships of those who maintain it, visit it, and activate it with community programs, plays into, in part, the persistent memory of yesterday's urban spaces (cf. Scherling 2015). We have observed the current discourse in pragmatic creative placemaking methodologies as well as in radical and subversive artistic urban interventions built on the premise of 're-imagining' vacant or blighted spaces. In encountering the lab, it becomes 'a monument to itself' and a symptom of nostalgia, associated with a new tradition of creative transformations of unused everyday spaces in postindustrial cities undergoing significant demographic and cultural change. The 'lab' as a spatial intervention implies notions of the future and of the past anticipating coming changes to urban life. In this light, for those who interact with Civic Art Lab, a nostalgic image of a small-scale, mixed-use community fabric of

5 Big Reuse is a New York City-based nonprofit retail outlet for salvaged and surplus building materials. Founded in 2005 , its mission is to divert materials from landfills, minimize carbon emissions, and provide communities with quality, low cost building materials and home furnishings.

62015 Civic Art Lab Artists, Designers, and Educators: Zoey Hart, Jess Kennedy, Ryan King, Mireille Liong, Amberle Reyes, Rebecca Sherman, stic.man of dead prez, Ashley Taylor, Caroline Voagen-Nelson, Alex Alaimo, sun|tect Architecture, Operation Resilient Long Island (ORLI). 
yesteryear is present. What Civic Art Lab does is ask what type of community spaces and institutions (even provisional or temporary) we lack in our current What it recalls is the classic urban standards of 'eyes on the street' environments. What it recalls is the che disappeared after the end of the $20^{\text {th }}$ century because of many historical forces of disinvestment, a shrinking middle class, changes in policing, creation of new social technologies, neoliberalism, and economic shifts (cf. Barnes et al. 2006; Holleran/Sam 2015; Jacobs 1961)

\section{REFLECTION}

What does it mean to reflect on a body of work?

The process of reflection has been an ongoing, multistep process of research, practice, critique, and self-criticism. By reflecting on the project developments of the past seven years, we consider how our earlier work (2011-2015) as the collective GreenspaceNYC culminated as Civic Art Lab (2015). This culmination was the outcome of nearly five years of practice-led, participatory research where we created temporary educational spaces and worked with different NYC communities and neighborhoods. We then engaged in the process of reflection and exhibited in Giessen (2016), held two more Civic Art Labs (2016 \& 2017), and expanded our process of reflection by incorporating dialogue as a type of reflection into this chapter (2017).

To structure our critical self-reflection and collaborative dialogue, we looked at various approaches from andragogy and pedagogy. Some of the questions that helped us to formulate our process and the design of our collaborative dialogue the authors outline the following:

Ask why something did or did not happen.

Ask what was good, why? What was bad, why? Neither good nor bad, but interesting, why?

Think of alternatives; what else could have happened? Why?

Look for other points of view.

Look for hidden assumptions in our attitudes and beliefs.

Look at something as a collection of parts but also as a set of qualities, values, and judgments. Look at the opposite viewpoint in order to challenge it.

actions. (ibid: $325-350$ )
In our 'expedition' to reflect on GreenspaceNYC and Civic Art Lab, these insights have consistently applied. The nomadic 'pop-up' style of GreenspaceNYC's interventions took us through distinctly different communities, where we are challenged to question our own assumptions, and consider diverse viewpoints (ibid: 325-350). John Dewey describes critical reflection as the "active, persistent, and careful consideration of any belief or supposed form of knowledge in the light of the grounds that support it and the further conclusions to which it includes a conscious and voluntary effort to establish belief upon a firm basis of evidence and rationality" (1933: 118). Thus, critical reflection involves more than pure logic; it deeply involves recognizing "the assumptions underlying our beliefs and actions" (Frid et al. 1998: 325). Through these exercises in self-reflection, as a collective, we operationalize our reasons and rationale for doing what we do: immersing ourselves in various NYC communities and cultures (cf. Brookfield 1988).

Picture 3: Civic Art Lab installation detail (ephemera and text)

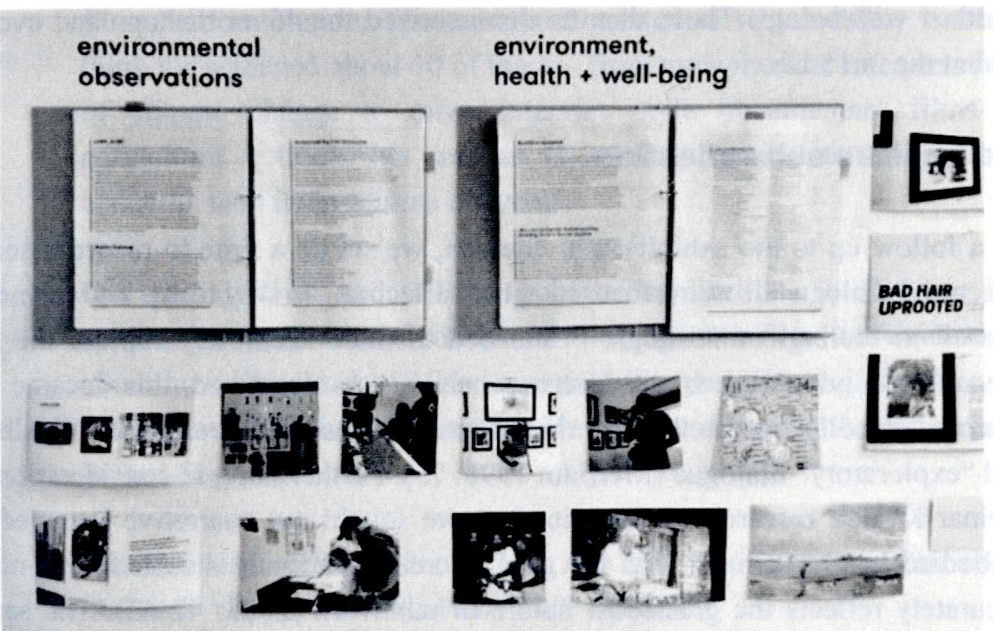

International Graduate Centre for the Study of Culture (GCSC), Justus-Liebig-University Giessen 2016. Courtesy of the authors. 


\section{Exhibition as self-reflection}

Our participation in For What It's Worth: Creative Encounters gave us the opportunity to think about the work we have done over the past years. During the exhibition, ongoing collaborations were observed between artists, businesses, local organizations, institutions, and the community at large. Our exhibition drew from our experiences as organizers, including an outline of the engagements pursued by each of the 15 volunteer educators and artists involved with the project, as a lens into these community-based collaborations. In the exhibition, we gave a retrospective of our 2015 Civic Art Lab - a storefront project hosted through our volunteer collective GreenspaceNYC. The installation at Giessen was processoriented and we invited the exhibition audience to interact with ephemera from the 2015 storefront, including full color snapshots of activities at the lab, as well as conceptual texts, descriptions, and testimonials of each workshop and creative investigations at the storefront that were organized according to three categories: 'exhibitions and workshops', 'environmental observations', and 'environment, health + well-being'. These themes characterized the 40 workshops and events held at the 2015 lab.

\section{Dialogue as self-reflection}

As a follow up to the exhibition in Giessen, we set up a time to record a semistructured dialogue. It was a focused act of reflection - a way to tap into memory, as well as feelings of nostalgia - intended to more accurately capture the full breadth of Civic Art Lab and GreenspaceNYC. As described, this became the central data collection method for this chapter because it encouraged a "flexible" and "exploratory" dialogue (Merriam 1998: 73). Furthermore, in consideration of Steinar Kvale's research on interviewing, we sought out "narrative knowledge, embodied in storytelling" with the goal of creating a lively discourse that more accurately reflects the grassroots nature of our work (2008: 42-43). The semistructured protocol was designed to include: a review of memorable workshops and expectations and some of the challenges we encountered; the experience of forming a large and informal collective; the relevance of the work; and, broadly, plans for the future. The dialogue (2017) was as follows:
Laura Scherling (LS): As part of our process of reflecting on GreenspaceNYC and Civic Art Lab, we have designed an informal interview.

Jeff Kasper (JK): We will talk about some of our experiences. Civic Art Lab is now going to the $4^{\text {th }}$ year.

LS: Our $4^{\text {th }}$ lab will continue to be held in New York City. For this chapter, we will start by reflecting on the $1^{\text {st }}$ lab - held in the Bedford Stuyvesant neighborhood, Brooklyn. Our $1^{\text {st }}$ lab was the focal point of our exhibition at the University of Giessen in Germany. Looking back to where this all started, I think we can take a moment to think about some of the memorable workshops and events from the very $1^{\text {st }}$ Civic Art Lab.

JK: One that immediately comes to mind is our sustainability film festival. ${ }^{7}$ Our team solicited films from filmmakers from around the world, short films, and animation. These were all related to sustainability issues. I think we screened about 10 of them - from metaphorical interpretations of climate change to more interview-style documentary films on agriculture. I think that was an interesting moment to bridge local concerns with international concerns.

LS: Our film festival had a large pool of applications ... I think 120 applicants. There was a lot of critical thinking in the films and animations about how climate change and sustainability are affecting our lives. At the time we held our lab, there were a couple of pop-up theater projects in Bed-Stuy.

JK: Another memorable part of Civic Art Lab was our exhibition about 'African' hair. It was called Bad Hair Uprooted.

7 GreenspaceNYC's Sustainability Film Festival was led by organizers Andrew Haner and Dan Bourbeau. 
Picture 4: Exhibit detail, Bad Hair Uprooted by Mireille Liong
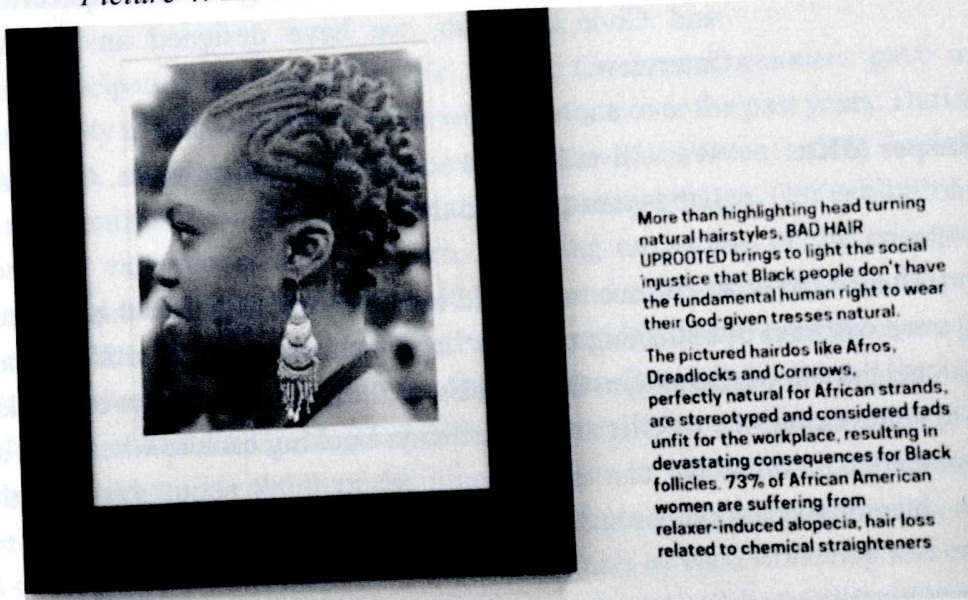

Civic Art Lab 2015. Courtesy of the authors

It was a celebration of black follicles, highlighting social injustice as it pertains to hair, featuring the work of Mireille Liong.

JK: Yes, the exhibition looked at how Black women and Black men are forced socially to adhere to standards about hair and use particular products that are unhealthy in order to be closer to a White/Caucasian standard. These types of hair treatments can be toxic to the body and to the environment. Through this exhibition, we were introduced to our neighbors, who are involved in a lot of different issues related to sustainability and social justice.

LS: We learned that sustainability is deeply intertwined with health issues, personal, public, and cultural. Mirielle's exhibition really drew from the Black culture and identity of Bed-Stuy, which is deeply ingrained in the neighborhood's history.

JK: This was one of the benefits of having a space like this - that we were able to really use that space to amplify the types of things our neighbors wanted to talk about.

LS:

The Bed-Stuy neighbors were enthusiastic to participate in Civic Art Lab exhibitions and workshops in a spontaneous fashion, and that was Local artists, designers, and environmentalists would walk into the storefront with project ideas. This really supported the notion of community-based sustainability, situated in a storefront where people can visibly observe what you're doing in the neighborhood.

JK: And to contribute, argue, and adjust that narrative.

LS: It has been rewarding to work together in this fashion. In another case, the final event of our $1^{\text {st }}$ lab, stic.man of the hip-hop group dead prez was willing to donate his time. He prepared a thorough, thoughtful presentation on sustainability and living healthily.

JK: stic.man's presentation on holistic living resonated with Bed-Stuy's residents. Frequently, in communities who embrace sustainability, we only hear from particular types of people and authors. To hear a famous hip-hop artist discuss how he lives his life with concern for issues of healthy living, self-care and organic foods was really inspiring.

LS: I was especially interested in his involvement with meditation practices and running. Stic.man creates community events to encourage running and various types of exercise. I have since taken up running in the park.

JK: That is awesome

LS: There were many other notable workshops and events. For example, Yasmeen Abdallah's tea ceremonies, where she takes discarded tea bags and reassembles them into sculptures.

JK: Also, a crowd favorite was Zoey Hart's Studio Subway workshop, which involved engaging people during their subway commutes, transforming it into a space for mindfulness and observation. During Zoey's workshops, participants could use the time to center themselves.

LS: We had some traditional environmental science educational classes as well. Architect Andrew Haner led a LEED certification course at no cost. ${ }^{8}$ Dan Bourbeau created a 'climate school', offering walk-in climate

8 Leadership in Energy and Environmental Design (LEED) is a rating system devised by the United States Green Building Council (USGBC) to evaluate the environmental performance of a building and encourage market transformation towards sustainable design. 
change education twice a week for several weeks. Our $1^{\text {st }}$ lab was a vibrant space and two months long. It was a lot to maintain a storefront project for two months.

It was. It involved making furniture and fixing things. It was somewhere between a laboratory and a classroom. We were there almost every day for two months. It was like the family business in some sense.

LS: Two months of offering free and low-cost education. Since the $1^{\text {st }}$ Civic Art Lab, we have hosted two more.

JK: The year after we left Bed-Stuy, we set up a shop in East Village in Alphabet City on Avenue C.

LS: We did change locations. We moved to a more central location in Manhattan. The East Village and Alphabet City have a lively, historic identity in art, music, and in furthering sustainable causes. The neighborhood has already gone through an intense amount of gentrification. There is a distinct economic divide in the area, but it is still a culturally vibrant place.

JK: There is much exchange of cultural practices in the area, a long history of activism from community gardens to squatting, and urban homesteading. We have been in the East Village/Alphabet City for two years, and we are going on the $3^{\text {rd }}$ year.

LS: We have considerably downsized the length of Civic Art Lab to a lon weekend. It means we can offer about 13 to 15 workshops and follow the model we established in Bed-Stuy, but it is more manageable in terms of finances, grant writing, and fundraising.

JK: By shortening Civic Art Lab from two months to around three days we have pared it down to the essential elements of what we have been doing It was not easy to do this; however, I think it offers a different type of long-term engagement than what we had when we were in Brooklyn. People come back to visit each year.

LS:

We have had some surprises along the way. What have you been surprised to learn about with our project?
JK: I was surprised to learn how much issues of sustainability do register in the "everyday" lives of people. And that is not to say that I did not think that they would matter, but more so of how they manifest themselves. For example, questions of wellness and African hair. That was a very specific everyday situation that I would not have thought about. It is beyond hot topics like recycling and clean energy. If we really sit down and think about what it would take to live a sustainable life, we would also have to think about the self and the 'cultural implications' of things like hair or materials. That is something that continues to surprise me.

LS: Sustainability permeates everything. From the food we buy to the clothing we wear, to the air that we breathe, to the water that we drink. I have always been impressed by the friendships that emerge out of Civic Art Lab. That has exceeded my expectations as well.

JK: What surprised me (in practice) is that people really do know how to lead the way forward and they need more spaces to experiment with and to share resources. Community spaces help to 'de-silo' people.

LS: 'De-silo' is an interesting word. It is not on an everyday basis that an environmental scientist can network with an upcycling artist, and an architect specializing in resilience. I think Civic Art Lab encourages these connections. More and more, we also see a lot of young children and their parents registering to participate. In terms of pedagogy, the instructors do a phenomenal job with curriculum design. We have always asked for hands-on, constructivist approaches to the way these courses are taught - from going on walks to visiting city gardens to looking at shorelines or infrastructure.

JK: These workshops also encourage participants to simply build something In Bed-Stuy, a woman came by to reflect on one of our workshops on composting. She mentioned that her grandson had never used his hands in this way before and since then, he will not stop talking about worms and organic foods.

LS: This year (2017), after Zoey Hart taught students to weave, they continued to weave in their free time and in between workshops. The tactility of weaving was a cathartic activity, and all the materials were upcycled. I think that is the case with a lot of GreenspaceNYC/Civic Art 
Lab workshops: complex topics in sustainability are simplified through hands-on activities.

JK: Hands-on activities about design and sustainability, in an everyday space like a storefront, situate this information at an approachable scale. I think that is incredible and continues to surprise me.

LS: Over the years, we have managed to sustain a large, informal community of designers, artists, volunteers, educators, neighbors, environmentalists, and activists. At the start of the project we imagined that DIY (Do it yourself) spaces, and sustainability, as it became more and more of a buzz-word, would eventually fall more in line with mainstream concerns. However, climate change has become a more of a concern in the US and throughout the world.

JK:

We still need community spaces that are non-institutional, grassroots and DIY. I think cultural traditions and 'futures' are completely smashing up against each other. And we have a lot of realities that people still need to talk about and work through in more informal settings. There is a lot of denial.

LS: There's a lot of climate denial in the Trump presidency. We are at a very specific moment in time where I feel like we are back-peddling. We are seven years into this project and we are still working through a lot of similar conversations. However, there is a new urgency ... Sustainability challenges are not resolved only locally but are evermore global issues. In the United States they are gaining some recognition at the state level, but not on a federal level. It's a little surreal for me.

JK: We are in a space where we need to redefine what we want the future to be; we're in a crisis period. There's a lot of space for imagination and a need for experimentation.

LS:

NYC is home to many sustainability and art projects which are also presented with funding challenges, political challenges, etc. What do we think are some of the benefits of creating this type of informal educational space in different communities of New York City?
JK: With Civic Art Lab, people teach each other on a more casual basis, and they share resources. Our participants learn about sustainability together. There's always been that type of dynamic with this project, the barriers to entry are low.

LS: I do think informal learning encourages participants to feel more empowered to come up with their own curriculum, to really teach or share something about sustainability that they care about and feel passionate about. Civic Art Lab's informal learning model eliminates the nitpicking, micromanaging, and it is more about delegation and support.

JK: We do have committee meetings every year where we invite the public to join in on this project. We learn (often) that people have a lot of skills to share. You mentioned empowerment. Spaces like Civic Art Lab are empowering because it allows us to reconsider what you could do as an individual, or what your organization can do.

LS: This idea of expanding skills to include sustainability reminds me of Andrew DeRosa's workshop on community, data mapping, and sustainability - that he has taught for two years at Civic Art Lab. Or Sohee Koo's workshop "Re-re-re-transforming the Ordinary" that looks at upcycling everyday objects. Andrew is a professor at Queens College while Sohee lectures at Columbia University. In their teaching, respectively, the courses are more art- and design-focused. During Civic Art Lab, they have generously designed a curriculum that integrates sustainability topics. 
Picture 5: Community Mapping workshop by Andrew DeRosa.

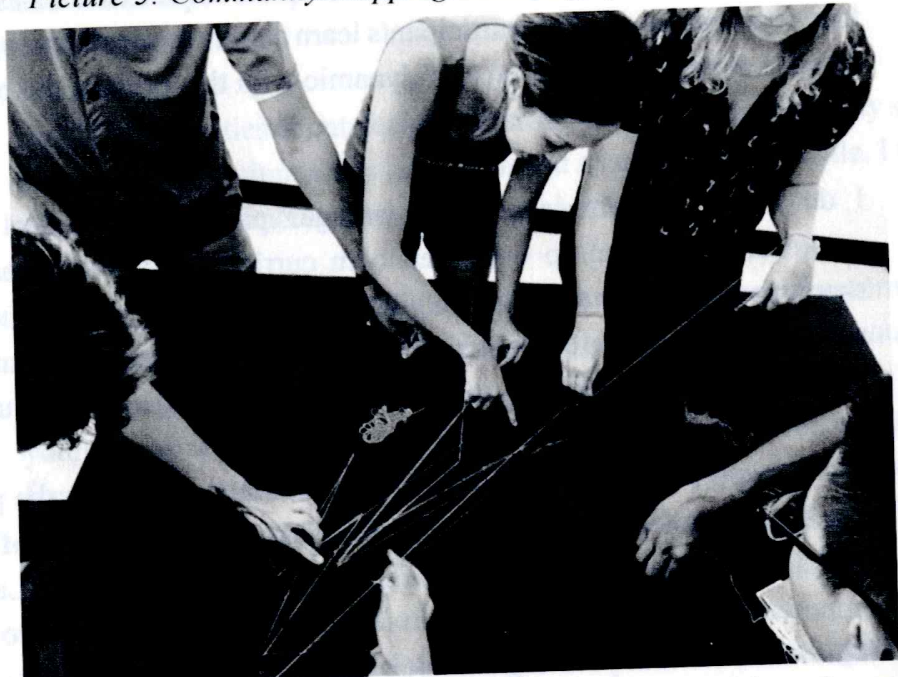

Civic Art Lab: Alphabet City New York 2016. Courtesy of the authors.

JK: Beyond our lab, it is critical for educators to rethink how waste and sustainability factor into their job. In that light, you do not necessarily need to be a director of policy or sustainability to make change happen. In our everyday lives, we can adjust, contributing to the larger systematic improvement. There's so much change that can happen ... Sometimes, it is not as a big of a leap as it seems. It is easy to perceive, "Oh no! What am I going to give up in my life to switch lifestyles?"

LS: Exactly! It is not always such a big deal. This reminds me of Agustina Besada's Civic Art Lab lecture about the circular economy - knowing where things come from, making incremental changes for sustainability. It reminds me of one of our earliest goals together for GreenspaceNYC/Civic Art Lab ... that sustainability should not be considered a luxury good.

JK:

This concept factors into some of our questions about the dangers of doing this type of work. We are all vulnerable in this process, confronting truths about where we live, ourselves, history, science, and more. There's always going to be aspects that are uncomfortable. It is challenging to amplify the concerns of the people who live in these neighborhoods that we work in. I think we try to be as people-focused as possible. It is important to consider how we can continue to build spaces that amplify
New Yorker's voices, our neighbors' voices, from different backgrounds and different directions. There are many discourses around artistic production, artists and galleries entering neighborhoods, fear of gentrification and displacement.

LS: It is a real challenge, acknowledging the relationships between art and gentrification, and reaching underserved populations in neighborhoods. I think this is something we are still learning how to do and that we are still trying to figure out ...

JK: Yes, how to reach more people through different types of barriers and how to go into a project with the support and direction from institutions, businesses, and organizations that collaborate with us.

LS: The $1^{\text {st }}$ Civic Art Lab emerged from a collaboration with Bridge Street. As we were talking about earlier in this interview, this gradually branched out into a network. In some ways, our partnership with the Norov brothers has been similar in the East Village/Alphabet City. The Norov brothers own a bike shop next door, where they do repairs. They care about the mission of sustainability and their neighbors.

JK: Yeah, to be linked up with local business and to find collaborators who've been in the neighborhood for a long time can really ground you in a particularly positive way.

LS: $\quad$ It would be great to eventually build more partnerships in rural parts of America. We have done a little bit of work in Detroit, but haven't gone very far. However, I still feel that NYC will continue to be our focus. This project has been site-specific.

JK: $\quad$ Aside from Manhattan and Brooklyn, we have worked on the periphery of New York City. We wanted to start on a scale that was intimate to us, relevant to us, and we have built a community for this project here ... I do think more and more about how our work can travel and what it means to do work outside of our community for this particular project.

LS: $\quad$ Taking the trip to Giessen is the reason why we are reflecting and why we wrote this chapter. By participating in 'For What It is Worth: Creative Encounters', we were able to get different perspectives and feedback. It 
was helpful to be somewhere else, thinking about Civic Art Lab, and reflecting on everything that has happened. What do you think about the experience we have had? Reflecting on our work from a totally different location, far from home, what does that do to us?

JK: I think it gives us a distance from what we do, because often we are so entangled in our daily lives and we are so exhausted from work that brings us somewhere else, mentally and physically. Reflection allows us to really boil down our ideas to the essentials and it also allows us to remember everything that has happened. It is challenging to have clarity while creating Civic Art Lab, during planning it. I am also really interested in having these types of reflection at home.

LS: I think we mainly reflect over coffee or over lunch, or on the phone. I would really look forward to ... in the next year ... to continue to take the time to reflect on Civic Art Lab. It is an excellent opportunity to build another exhibition about Civic Art Labs 1, 2, and 3.

JK: Based on our research, exhibitions are an effective tool for reflection. An exhibition can be a way of being self-critical; you're considering what you've done, things that went well, and what could be better. I think it is an important practice to be self-reflective. And I'm excited to keep doing that.

LS: Yes. I agree. I think that is a good note to end on here. On a note of selfreflection.
Picture 6: Installing an exhibit on invasive urban flora.

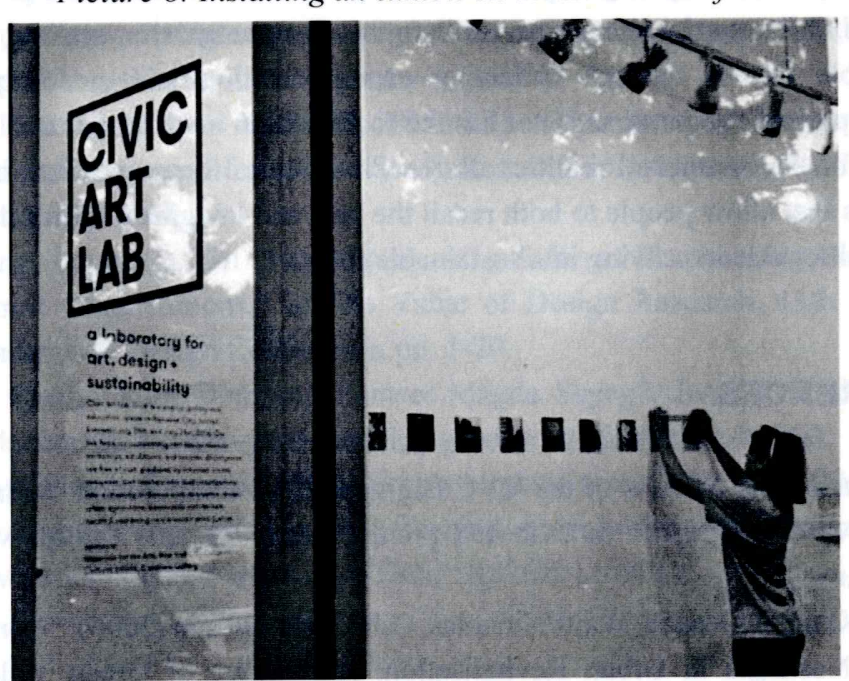

Civic Art Lab: Alphabet City New York 2016. Courtesy of the authors.

\section{CONCLUSION}

As described in this chapter, Civic Art Lab aims to bridge the divide between disciplinary silos and the applied practices of artists, designers, activists, environmentalists, and everyday New Yorkers. Civic Art Lab has strived to provide a free educational community space, while continually emphasizing that sustainability is 'not a luxury good'. Sustainability can create meaningful relationships between art, design, and grassroots social movements through the exchange of valuable skills, experiences, and expertise in a non-hierarchical way, simply through starting conversations with neighbors and learning through handson activities. Our community-based interventions and research have taught us that sustainability can be 'accessible'. This is arguably a fundamental notion to making sustainability practices a part of our everyday lives, especially in countries like the US, where an enormous amount of waste is produced. When meaningful multidisciplinary grassroots relationships are established in favor of sustainability, these actions are also committed to memory. By carrying these memories and embracing "a way of being nostalgic for the future," one can imagine the motivation to engage in non-hierarchical sustainability practices in all facets of everyday life (Davies 2010).

Through this project, we hope that non-hierarchical exchanges will reinforce sustainability and influence participants in our projects, and others like these, to 
replicate sustainability-driven practices. Civic Art Lab will continue to promote localized, DIY, participatory interventions between neighbors, seeking to build sustainable futures through collective experimentation and creativity. As a creative project, the purpose is not limited to education in economic and political systems or environmental realities. Rather, it seeks to forge connections across networks that allow people to both recall the past and imagine realities that bring communities closer to living in a sustainable future.

\section{REFERENCES}

"Announcing the winners of the NYC BigApps 2017 competition! Winners will receive over $\$ 30,000$ in cash and prizes!", May 23, 2017 (http://www.big apps.nyc).

Barnes, Kendall/Gordon, Waitt/Nicholas, Gill/Chris, Gibson (2006): "Community and Nostalgia in Urban Revitalisation: A Critique of Urban Village and Creative Class Strategies as Remedies for Social 'Problems'." In: Australian Geographer 37/3, pp. 24-60.

Brookfield, Stephen (1988): "Developing Critically Reflective Practitioners: A Rationale for Training Educators of Adults." In Stephen Brookfield (ed.), Training Educators of Adults: The Theory and Practice of Graduate Adult Education, New York: Routledge, pp.317-338.

"Creative Communities and Arts-based Placemaking", June 12, 2015 (https:// www.pps.org/article/creative-communities-and-arts-based-placemaking).

“Creative Placemaking Resources”, 2017 (https:/www.arts.gov/artistic-fields/ creative-placemaking/creative-placemaking-resources).

Davies, Jeremy (2010): "Sustainable Nostalgia." In Memory Studies 3, Thousand Oaks: SAGE Journals, pp. 262-268.

Dewey, John (1933): How We Think: A Restatement of the Relation of Reflective Thinking to the Educative Process, Lexington, MA: Heath.

Frid, Sandra/Reading, Chris/Redden, Ted (1998): “Are teachers born or made? Critical reflection for professional growth," in Maxwell T., (ed.), The Context of Teaching, Armidale NSW: Kardoorair Press, pp. 325-350.

Gehl, Jan (2011): Life between buildings: Using Public Space, Washington, D.C.: Island Press.

Gehl, Jan (2013): Cities for People, Washington, D.C.: Island Press.

Jacobs, Jane (1961): The Death and Life of Great American Cities, New York: Random House.

Kvale, Steinar (2008): Doing Interviews, Thousand Oaks, CA: Sage.
"Lab City: The Limits of Pop-up Problem Solving. Dissent", July 22, 2015 (https:/www.dissentmagazine.org/online_articles/lab-city-the-limits-of-popup-problem-solving-ideas-city-new-museum).

“Open Data for All New Yorkers", 2017, (https://opendata.cityofnewyork.us).

Revised and Expanded from Case Study Research in Education, San Francisco, CA: Jossey-Bass.

Scherling, Laura (2015): "How Mapmaking Informs Placemaking Practices in Detroit Organizations," in The Value of Design Research, 11th European Academy of Design Conference, pp. 1-20.

"She's Crafty: Yarn Bombing Pioneer Magda Sayeg”, Jun 18, 2013 (designmilk.com/shes-crafty-yarn-bombing-pioneer-magda-sayeg-knitta).

"Website aims to Transform New York's blighted areas", March 1, 2011 (http:// www.reuters.com/article/us-web-newyork-green/website-aims-to-transformnew-yorks-blighted-areas-idUSTRE71R57620110301). 